\title{
EMOTION RECOGNITION IN BORDERLINE PERSONALITY DISORDER-A REVIEW OF THE LITERATURE
}

\author{
Gregor Domes, PhD, Lars Schulze, MSc, and Sabine C. Herpertz, MD
}

\begin{abstract}
Borderline personality disorder (BPD) is characterized by distinct impairments in emotion regulation, resulting in affective instability especially in the social context. It has been suggested that impaired social cognitive functioning such as impaired facial emotion recognition contributes to the social disturbances in BPD. In accordance with this notion, a number of behavioral studies have revealed a pattern of alterations in facial emotion recognition associated with BPD: subtle impairments in basic emotion recognition, a negativity or anger bias, and a heightened sensitivity to the detection of negative emotions. Furthermore, there is increasing evidence for structural and functional changes in the neural networks underlying affective dysregulation and emotional hyperreactivity in BPD. Merging these lines of evidence, we propose that emotional hyperreactivity interferes with the cognitive processes of facial emotion recognition, thereby contributing to the specific pattern of altered emotion recognition in BPD. Suggestions for future research and clinical implications are discussed.
\end{abstract}

Borderline personality disorder (BPD) is characterized by a pervasive pattern of emotional instability, unstable interpersonal relations, and impaired impulse control. The most prominent clinical symptoms are recurrent self-injury, impulsive aggression and chronic suicidal tendencies, severely affecting patients and their social environment (Lieb, Zanarini, Schmahl, Linehan, \& Bohus, 2004). Deficits in emotion regulation have been considered a hallmark of BPD (Linehan, 1993) and it has been argued that the social problems of BPD patients mainly arise from impaired

From University of Zurich, Zurich, Switzerland (G. D.); and University of Rostock, Rostock, Germany (L. S., S. C. H.).

We thank two anonymous reviewers for their valuable comments on an earlier version of the manuscript. The preparation of the manuscript was in part supported by grants from the Deutsche Forschungsgemeinschaft (DFG He 2660/7-1). The authors declare no competing financial interest.

Address correspondence to Sabine C. Herpertz, M.D., Department of Psychiatry and Psychotherapy, University of Rostock, Gehlsheimer Strasse 20, 18147 Rostock, Germany; E-mail: sabine.herpertz@med.uni-rostock.de 
emotion regulation. BPD patients have been described as highly vigilant for social stimuli, especially for social cues that signal social threat or rejection (Linehan, 1995). Recently, a field study revealed that social situations are potent triggers for emotional arousal and affective instability in BPD (Ebner-Priemer et al., 2007).

The ability to accurately infer the mental state of others from external cues such as facial emotional expressions is essential for guiding one's own behavior and regulating one's own emotional state in the social context. Thus, facial emotion recognition can be considered a cognitive cornerstone for intact social functioning. Consequently, the capability to recognize the internal state from external cues can be seen as a cognitive basis of social functioning and might promote empathy, trust, and prosocial behavior (Marsh \& Ambady, 2007). In turn, misinterpretations due to impaired recognition are likely to result in emotional disturbances, inadequate social behavior, and impaired social functioning in psychiatric conditions.

Given the immense importance of emotion recognition in social interactions, it is not surprising that emotion recognition has been extensively investigated in psychiatric conditions, with most of the studies examining participants' ability to recognize basic emotions from facial expressions. Facial emotion recognition is impaired in several disorders, such as schizophrenia (Kohler et al., 2003), autism spectrum disorders (Bolte \& Poustka, 2003), depression (Leppanen, 2006), anxiety disorders (Montagne et al., 2006; Simonian, Beidel, Turner, Berkes, \& Long, 2001), antisocial personality disorder and psychopathy (Blair, Colledge, Murray, \& Mitchell, 2001) as well as neurodegenerative disorders such as Alzheimer's disease and Parkinson's disease (Kohler et al., 2005; Sprengelmeyer et al., 2003). In sum, these studies suggest that impairments of emotion recognition are probably due to various causes and are not specific to a single disorder or psychopathological aspect.

Clinical observations have led to the hypothesis that the underlying neural basis for these alterations in emotion recognition differs between patients with BPD and those with other psychiatric conditions. Given the distinct deficits in regulating negative emotions in BPD, we hypothesize that the alterations in emotion recognition in BPD reviewed in the present paper mainly arise from interference of enhanced emotional arousal with the cognitive evaluation of the emotional facial expressions.

The present review aims to integrate both behavioral studies on emotion recognition and the increasing number of structural and functional imaging studies in order to explore the neural basis of emotion recognition abnormalities observed in BPD. We begin by reviewing the literature on facial emotion recognition in BPD followed by an overview of the existing literature referring to the neural correlates of emotion recognition and emotional processing in BPD. Finally, we attempt to merge these complementary lines of research, deriving suggestions for future research. 


\section{FACIAL EMOTION RECOGNITION IN BPD}

Linehan proposed that the emotional vulnerability of BPD patients is due to enhanced emotional sensitivity, increased emotional reactivity and a slower return of emotional arousal to baseline (Linehan, 1993). Accordingly, BPD patients have been expected to show enhanced social sensitiv-

ity, which is reflected by increased vigilance for social cues, especially for cues that signal social rejection or threat (Wagner \& Linehan, 1999). Thus, it has been assumed that BPD patients show enhanced sensitivity to facial emotional expressions, resulting in a lower detection threshold and increased accuracy in the detection of emotions.

We found six studies that explicitly addressed facial emotion recognition in BPD (Table 1). In the first published study, Levine and coworkers presented expressions of basic emotions from the "Pictures of Facial Affect" (Eckman \& Friesen, 1976) and found that borderline patients were less accurate in terms of emotion recognition, especially for expressions of anger, disgust, and fear (Levine, Marziali, \& Hood, 1997). This result was replicated and extended by Bland, Williams, Scharer, and Manning (2004), who found in their study that recognition accuracy was impaired for fearful, angry, and sad faces. Furthermore, Bland et al. were able to show that self-reported negative affect in terms of everyday life events was inversely correlated with emotion recognition accuracy (Bland et al., 2004). However, another study that used static facial expressions of basic emotions did not confirm the previous results, but showed impaired emotion recognition when appraisals of combined facial expressions and affective prosody were made (Minzenberg, Poole, \& Vinogradov, 2006). All of these studies used a multiple-choice approach; i.e., subjects were asked to choose the answer from a list of alternatives. In contrast, Wagner and Linehan asked participants to verbally describe the emotional state of the presented person. Using this approach, they were able to show enhanced facial emotion recognition in the BPD group for fearful faces and a tendency in this group to over-report fear when presented with neutral facial expressions (Wagner \& Linehan, 1999). This effect was interpreted as reflecting a negativity bias in the evaluation of ambiguous facial expressions in BPD. Using static emotional facial expressions, it remains unclear whether BPD patients exhibit an altered detection threshold especially for ambiguous stimuli, or whether they show differences in the accuracy of labeling specific emotions.

Therefore, another two studies used a different approach in order to examine detection threshold and recognition accuracy simultaneously. In these studies, pictures of facial affect were electronically morphed from a neutral expression to basic emotional expressions with increasing intensity (cf. Blair \& Curran, 1999). The first study demonstrated that participants with BPD correctly classified facial emotions at a lower level of intensity (Lynch et al., 2006). A study from our laboratory contradicts these results, as we were not able to show enhanced sensitivity in terms of a reduced detection threshold (Domes et al., 2008). However, our results 
TABLE 1. Experimental Studies Addressing the Issue of Facial Affect Recognition in Patients with Borderline Personality Disorder

\begin{tabular}{|c|c|c|c|c|}
\hline Study & $\begin{array}{c}\text { Patients' age, comorbidity, } \\
\text { medication, exclusion criteria }\end{array}$ & Control group & $\begin{array}{c}\text { Task stimuli, processing, } \\
\text { affect categories }\end{array}$ & Key findings \\
\hline $\begin{array}{l}\text { Bland et al., } \\
2004\end{array}$ & $\begin{array}{l}35 \text { women; age } 18-48 \\
91 \% \text { with sexual abuse; } 66 \% \\
\text { with major depression } \\
\text { medication: n/a } \\
\text { E.C.: psychosis, bipolar disorder, } \\
\text { substance abuse }\end{array}$ & $\begin{array}{l}35 \text { healthy women; total sample } \\
\text { age: } 32.3 . \pm 8.5 \\
\text { no age difference between groups } \\
\text { higher educational level than } \\
\text { BPD }\end{array}$ & $\begin{array}{l}\text { POFA } \\
\text { Forced-choice format }\end{array}$ & $\begin{array}{l}\text { BPD patients less accurate; es- } \\
\text { pecially for anger, disgust } \\
\text { and sadness } \\
\text { negative correlation between } \\
\text { accuracy and intensity of } \\
\text { negative affect }\end{array}$ \\
\hline $\begin{array}{l}\text { Domes et } \\
\text { al., } 2008\end{array}$ & $\begin{array}{l}25 \text { women; age } 26.0 \pm 7.2 \\
64 \% \text { with sexual abuse; } 44 \% \\
\text { with current PTSD; } 40 \% \text { with } \\
\text { psychiatric medication } \\
\text { E.C.: neurological signs, MDD, } \\
\text { panic disorder, generalized anx- } \\
\text { iety disorder, social phobia, ma- } \\
\text { jor somatic illness, substance } \\
\text { abuse }\end{array}$ & $\begin{array}{l}25 \text { healthy women; age } 25.9 \pm \\
4.5 \\
\text { matched for age, education and } \\
\text { IQ at the group level }\end{array}$ & $\begin{array}{l}\text { 1. POFA (morphed basic emo- } \\
\text { tional intensity; } 5 \% \text { steps) } \\
\text { presentation stopped after } \\
\text { first response } \\
\text { 2. POFA (blends of two basic } \\
\text { emotions; e.g. } 90 \% \text { anger/ } \\
10 \% \text { fear); forced-choice } \\
\text { format }\end{array}$ & $\begin{array}{l}\text { 1. No differences in detection } \\
\text { threshold } \\
\text { BPD group showed reduc- } \\
\text { tion of recognition threshold } \\
\text { over time } \\
\text { 2. Bias towards the perception } \\
\text { of anger }\end{array}$ \\
\hline $\begin{array}{l}\text { Levin et al., } \\
1997\end{array}$ & $\begin{array}{l}20 \text { women and } 10 \text { men } \\
\text { age: } \mathrm{n} / \mathrm{a} \\
\text { comorbidity: } \mathrm{n} / \mathrm{a} \\
\text { medication: } \mathrm{n} / \mathrm{a} \\
\text { exclusion criteria: } \mathrm{n} / \mathrm{a}\end{array}$ & $\begin{array}{l}30 \text { healthy volunteers }(\mathrm{m} / \mathrm{f} 15 / \\
15) ; \text { total sample age: } 23-56 \\
(37.6 \pm 7.8) \\
\text { matched for age and educational } \\
\text { level }\end{array}$ & $\begin{array}{l}\text { POFA } \\
\text { Forced-choice format }\end{array}$ & $\begin{array}{l}\text { Impaired accuracy in emotion } \\
\text { recognition; especially for } \\
\text { anger, disgust, and fear }\end{array}$ \\
\hline $\begin{array}{l}\text { Lynch et } \\
\text { al., } 2006\end{array}$ & $\begin{array}{l}17 \text { women and } 3 \text { men; age: } 35.5 \\
\pm 11.2 \\
65 \% \text { with psychiatric medication } \\
\text { E.C.: current mania, history of } \\
\text { psychosis }\end{array}$ & $\begin{array}{l}20 \text { healthy volunteers; } 34.7 \pm \\
11.2 \\
\text { No differences in age, gender, eth- } \\
\text { nicity and educational level }\end{array}$ & $\begin{array}{l}\text { POFA (morphed basic emo- } \\
\text { tional intensity; } 2.5 \% \text { steps) } \\
\text { Multiple responses possible }\end{array}$ & $\begin{array}{l}\text { BPD patients showed lower de- } \\
\text { tection threshold, regardless } \\
\text { of valence }\end{array}$ \\
\hline $\begin{array}{l}\text { Minzenberg } \\
\text { et al., } \\
2006\end{array}$ & $\begin{array}{l}38 \text { women and } 5 \text { men, outpa- } \\
\text { tients } \\
\text { age } 35 \pm 13 \\
77 \% \text { with psychiatric medication } \\
\text { E.C.: neurological disease, psy- } \\
\text { chosis, bipolar disorder, cur- } \\
\text { rent PTSD, MDD, substance de- } \\
\text { pendence }\end{array}$ & $\begin{array}{l}26 \text { healthy volunteers } \\
\text { age } 34 \pm 9 \\
\text { not more than one criterion for } \\
\text { BPD nor close to the screening } \\
\text { threshold for other PD } \\
\text { higher educational level than } \\
\text { BPD }\end{array}$ & $\begin{array}{l}\text { 1. POFA basic emotion } \\
\text { 2. Bell-Lysaker Emotion Rec- } \\
\text { ognition Test (BLERT) } \\
\text { 3. Buss-Durkee Hostility In- } \\
\text { ventory (BDHI) }\end{array}$ & $\begin{array}{l}\text { 1. No difference in accuracy } \\
\text { and RT } \\
\text { 2. Lower accuracy in multi- } \\
\text { modal emotion recognition; } \\
\text { accuracy inversely corre- } \\
\text { lated with BDHI score (sus- } \\
\text { piciousness and assault) }\end{array}$ \\
\hline $\begin{array}{l}\text { Wagner \& } \\
\text { Linehan, } \\
1999\end{array}$ & $\begin{array}{l}21 \text { women (and a history of sex- } \\
\text { ual abuse); age } 18-45(29.7 \pm \\
5.9) \\
\text { comorbidity: } \mathrm{n} / \mathrm{a} \\
\text { medication: } \mathrm{n} / \mathrm{a} \\
\text { E.C.: psychoses or substance } \\
\text { abuse }\end{array}$ & $\begin{array}{l}21 \text { women with history of child- } \\
\text { hood sexual abuse, but no } \\
\text { BPD; age } 35.3 \pm 7.4 \\
20 \text { healthy women without his- } \\
\text { tory of abuse; age } 31.6 \pm 7.1 \\
\text { higher educational level than } \\
\text { BPD }\end{array}$ & $\begin{array}{l}\text { JACFEE } \\
\text { Free-response format }\end{array}$ & $\begin{array}{l}\text { BPD over-reported fear; no dif- } \\
\text { ferences for other emotions } \\
\text { Impaired recognition of neu- } \\
\text { tral slides (bias towards neg- } \\
\text { ative answers) }\end{array}$ \\
\hline
\end{tabular}
$6 \pm 7.8$

level

11.2

o differences in age, gender,

26 healthy volunteers

age $34 \pm 9$

criterion for

threshold for other PD

igher educational level than

21 women with history of childhood sexual abuse, but no

BPD; age $35.3 \pm 7.4$

BPD

Notes. POFA, Pictures of Facial Affect; JACFEE, Japanese and Caucasian Facial Expressions of Emotion; E.C., Exclusion criteria 
provide first evidence for enhanced "learning" over the course of the experiment in the BPD group; i.e., patients showed a significant reduction in detection threshold over the course of the experiment, whereas the control group did not. This "learning" effect in the BPD group might reflect enhanced sensitivity to the emotional expression of familiar faces in particular. Within this study, a second task with ambiguous blends of facial expression was applied, revealing a response bias towards the perception of anger in the BPD group. BPD patients tended to significantly overreport anger when evaluating ambiguous blends of anger and sadness, and anger and happiness.

The divergent results in the morphing task used by Lynch et al. (2006) and Domes et al. (2008) could be due to subtle differences in the experimental design. In the Lynch study, participants were allowed to change their mind as often as they liked during a single trial, whereas in the study from our lab, the trial was stopped following the first response. Thus, the influence of guessing is likely to vary between the studies. Another aspect to be considered is the time pressure under which the response had to be given. In the study by Domes et al., participants labeled the facial stimuli without time restraints after stopping the presentation, whereas in the Lynch study the responses had to be given during the presentation. Hence, factors other than emotional sensitivity, such as impulsivity, motor speed or attention, might have differentially affected the participants' responses in the two studies.

The characteristic deficits of emotion recognition in patients with BPD contradict the assumption of general hypersensitivity to facial emotions in $\mathrm{BPD}$, and rather suggest subtle impairments in labeling accuracy accompanied by a bias towards negative emotions; i.e., a tendency to interpret ambiguous faces in a more negative way. The reported negativity bias in emotion recognition and the evaluation of others (Arntz \& Veen, 2001; Wagner \& Linehan, 1999), and the bias towards the perception of anger (Domes et al., 2008) in particular, might reflect the anticipation of rejection or social threat. This notion is in line with typical cognitions of BPD patients previously outlined by Pretzer et al. (1990), which suggest that BPD patients see the world and others as dangerous, and themselves as powerless and unacceptable.

To date, only two functional imaging studies have explicitly investigated the neural responses to emotional faces in BPD patients (Donegan et al., 2003; Minzenberg, Fan, New, Tang, \& Siever, 2007). However, since both of them found abnormalities in the prefrontal-amygdala neurocircuitry mediating affect regulation, this network may be an important focus for providing an understanding of the observed behavioral alterations in facial emotion recognition.

\section{NEUROIMAGING FINDINGS RELATING TO FACIAL EMOTION RECOGNITION AND EMOTIONAL PROCESSING IN GENERAL}

Over the last decades, there have been several attempts to merge evidence from lesion studies and functional imaging into a theoretical framework of 
the neural basis of face perception (Adolphs, 2002; Haxby, Hoffman, \& Gobbini, 2002; Posamentier \& Abdi, 2003). Taken together, these models propose a core system of face perception comprising the extrastriate cortex, parts of the fusiform gyrus and superior temporal sulcus and extended systems that modulate activity of the core system, integrating attention, memory, conceptual knowledge and emotion. These modulatory areas comprise the anterior cingulate cortex (ACC), the hippocampus, the insula and the amygdala, with the latter two being specifically involved in the processing of emotionally laden facial stimuli (Adolphs, 2002).

Besides the general role of the amygdala and associated areas as the neural basis for emotion and vigilance (Davis \& Whalen, 2001), there is accumulating evidence that intact neurocircuitry within the amygdala is essential for intact emotion recognition (Adolphs \& Spezio, 2006). Patients with lesions of the amygdaloid complex show impaired recognition of negative (especially fearful) facial expressions (Adolphs, 2007; Adolphs et al., 2005; Adolphs \& Tranel, 2003; Adolphs, Tranel, Damasio, \& Damasio, 1994; Adolphs, Tranel, Damasio, \& Damasio, 1995; Adolphs et al., 1999; Hamann \& Adolphs, 1999) and mental state attributions in general (Adolphs, Tranel, \& Damasio, 1998; Stone, Baron-Cohen, Calder, Keane, \& Young, 2003). In addition, there is considerable agreement among functional imaging studies that the perception of facial emotions is associated with amygdala activity (Fitzgerald, Angstadt, Jelsone, Nathan, \& Phan, 2006; Phan, Wager, Taylor, \& Liberzon, 2002; Phan, Wager, Taylor, \& Liberzon, 2004). Due to its extensive reciprocal connections to cortical as well as brainstem areas (Young, Scannell, Burns, \& Blakemore, 1994), the amygdala is thought to not only modulate emotional responding, but also to interact with cognitive processes (Phelps, 2006). Indeed, there is accumulating evidence that the amygdala modulates other brain regions involved in the cognitive processing of social stimuli; e.g., the lateral fusiform gyrus, the inferior occipital lobe, superior temporal sulcus and cingulate cortex (Vuilleumier \& Pourtois, 2007). Although emotion is thought to guide cognition by reallocating cognitive resources (Bechara, Damasio, \& Damasio, 2003; Damasio, 1996; Glascher, Rose, \& Buchel, 2007), a number of studies have shown that emotional arousal can disturb cognitive processes, such as attention (Erthal et al., 2005), working memory (Dolcos \& McCarthy, 2006) and inhibition of interference (Etkin, Egner, Peraza, Kandel, \& Hirsch, 2006). Dolcos and colleagues showed that emotional arousal interferes with working memory for social stimuli and that the interference was associated with high amygdala activity (Dolcos \& McCarthy, 2006). In BPD, interference between emotion and cognition has been demonstrated by several studies (Arntz, Appels, \& Sieswerda, 2000; Domes et al., 2006; Korfine \& Hooley, 2000; Sieswerda, Arntz, Mertens, \& Vertommen, 2007). Arntz and co-workers, for example, found impaired performance in an emotional Stroop paradigm when arousing stimuli of negative valence were presented (Arntz et al., 2000; Sieswerda et al., 2007). 
A number of studies have reported structural as well as functional abnormalities in the amygdala in BPD. The majority of structural studies found significant amygdala volume reductions in BPD (Driessen et al., 2000; Rusch et al., 2003; Schmahl, Vermetten, Elzinga, \& Douglas Bremner, 2003; Tebartz van Elst et al., 2003; Tebartz van Elst et al., 2007), although other studies failed to find differences in amygdala volume (Brambilla et al., 2004; New et al., 2007; Zetzsche et al., 2006). Using fMRI, an initial study found increased blood oxygen level-dependent (BOLD) responses in the bilateral amygdala in response to negative stimuli from the International Affective Picture System (IAPS) in BPD (Herpertz et al., 2001). Furthermore, marked bilateral activations of the fusiform gyrus and activations of the medial and inferior lateral frontal cortex were found in BPD patients. Donegan and colleagues (2003) presented pictures of emotional faces and found enhanced left-sided amygdala reactivity in BPD patients to emotional faces, regardless of their specific valence (Donegan et al., 2003). In a study comparing BPD patients with and without comorbid post-traumatic stress disorder, Driessen et al. (2004) found enhanced amygdala responding in the BPD/PTSD group for trauma-related memories. Recently, another study demonstrated specifically enhanced neural activation of the right amygdala in BPD in response to fearful faces compared to neutral faces, along with attenuated activations of the rostral ACC (Minzenberg et al., 2007).

The dorsolateral PFC (dlPFC) and the orbito-frontal cortex (OFC) have been implicated in the voluntary suppression of negative emotions (Eippert et al., 2007; Ochsner, Bunge, Gross, \& Gabrieli, 2002), whereas the medial $\mathrm{PFC}(\mathrm{mPFC})$ has been associated with the self-referential processing and regulation of emotion (Ochsner et al., 2004). The ACC has close connections to subcortical structures as well as to the mPFC (Devinsky, Morrell, \& Vogt, 1995). The dorsal section of the ACC has been associated with cognitive tasks challenging attention, whereas the rostral section seems to be involved in the modulation of emotional arousal (Bush, Luu, \& Posner, 2000).

In BPD, structural and functional abnormalities in these regulatory areas have been demonstrated in several studies. Starting with a structural MRI study which reported reduced total volume of the frontal lobe in BPD patients (Lyoo, Han, \& Cho, 1998), subsequent studies showed increased white matter volume in the anterior and medial part of the PFC (Hazlett et al., 2005), but no total volume differences in the dorsolateral region (Brambilla et al., 2004; Hazlett et al., 2005; Tebartz van Elst et al., 2003). Other studies found structural abnormalities of white and gray matter in the OFC associated with BPD (Rusch et al., 2007; Tebartz van Elst et al., 2003). Reduced volume of the ACC (Tebartz van Elst et al., 2003), as well as reduced gray matter and enhanced white matter volume in the medial cingulate have been reported in BPD (Hazlett et al., 2005). Investigating functional abnormalities, a number of (resting) positron emission tomography (PET) and magnetic resonance spectroscopy studies 
found reduced metabolism in the PFC and the ACC in BPD patients compared to healthy controls (De La Fuente et al., 2997; Soloff, Meltzer, Greer, Constantine, \& Kelly, 2000; Tebartz van Elst et al., 2003; Tebartz van Elst et al., 2001) whereas others found a hypermetabolism in frontal and prefrontal areas (Juengling et al., 2003). A recently published PET study showed that the coupling of OFC and amygdala metabolism normally found in healthy controls was absent in BPD (New et al., 2007). Investigating functional abnormalities, studies using fMRI found blunted responses in the PFC to trauma-related memories (Schmahl, Vermetten, Elzinga, \& Bremner, 2004) and enhanced responding in the bilateral dlPFC to the imagery of abandonment (Schmahl, Elzinga, et al., 2003) and painful stimulation (Schmahl et al., 2006) as well as heightened activity in bilateral OFC during autobiographical memory retrieval (Schnell, Dietrich, Schnitker, Daumann, \& Herpertz, 2007). A recently published study reported attenuated activations in the ventral $\mathrm{MPFC}$, medial OFC, and the subgenual ACC in BPD patients during response inhibition to words of negative valence (Silbersweig et al., 2007).

Taken together, brain imaging studies suggest that BPD patients show structural and functional alterations in a frontolimbic network, in particular reduced amygdala volume and enhanced amygdala responding to emotional stimuli such as negative scenes and facial expressions. In addition, there is some evidence for structural abnormalities in the prefrontal cortex and functional alterations in the context of pain perception, memory retrieval, response inhibition, and the processing of emotional stimuli. These abnormalities have been interpreted as reflecting deficits in emotion regulation in BPD (Johnson, Hurley, Benkelfat, Herpertz, \& Taber, 2003).

\section{SUMMARY AND SUGGESTIONS FOR FUTURE RESEARCH}

The structural and functional abnormalities in parts of the neural network subserving emotional information processing reviewed above, i.e., amygdala hyperreactivity in concert with regulatory deficits of the OFC and the $\mathrm{PFC}$, might suggest that emotional arousal interferes with social cognitive processing and might contribute to the characteristic alterations in facial emotion recognition. The results by Donegan et al. (2003) and Minzenberg et al. (2007) indeed demonstrate that BPD patients show enhanced limbic reactivity to emotional facial expressions. Thus, the emotional dysregulation of BPD patients might subserve the pattern of alterations in facial emotion recognition, which is characterized by an enhanced sensitivity towards negative emotions as well as by a tendency to label ambiguous or neutral stimuli more negatively or as more angry.

It is important to note that this hypothesized relationship between emotional reactivity and facial emotion recognition was not investigated directly in the behavioral and imaging studies outlined above. Thus, in future studies, the challenge of social cognitive processes such as facial emotion recognition during states of varying emotional arousal could be a 
promising approach to directly test for the proposed interference of emotional hyperreactivity and social cognition in BPD.

Furthermore, the reported studies are limited to basic emotional stimuli. In most cases, standardized static pictures of faces were presented. However, social interaction in everyday life is much more complex and dynamic, and people normally rely on more than one sensory modality when evaluating the emotional state of another person. Thus, future studies could extend the experimental setting and begin to examine the ability of BPD patients to recognize emotional states of others in more complex scenes, which are closer to interactions in everyday life. Such multimodal tasks could involve the integration of visual and auditory information. First steps in this direction have been taken by Minzenberg et al. (2006), who showed impaired emotion recognition in BPD patients compared to healthy participants in a task involving the integration of visual and auditory emotional cues. Employing dynamic video stimuli , such as the "Movie for the Assessment of Social Cognition (MASC)," recently introduced by Dziobek et al. (2006), might be another approach to assess alterations in the perception of third person interactions. These studies might provide information on other dysfunctional brain circuits in addition to the prefontal-amygdala circuit which probably contribute to the specific peculiarities in social cognition typical of BPD patients.

It should be noted that the observed alterations in emotion recognition of BPD patients might also be attributed to personality dimensions and symptoms other than emotional dysregulation, e.g., aggression, cognitive impulsivity, dissociation, and identity disturbance. Each of these symptoms may significantly impact on social cognitive functioning thereby potentially affecting facial emotion recognition.

Together with the reported heterogeneity of the samples studied in the reviewed articles, it might be promising to focus on psychopathologically relevant trait dimensions such as emotional instability, impulsivity, anxiety or anger/aggression rather than on nosological categories or disorders. Another approach might be to control for psychopathological confounds by comparing BPD patients with other psychiatric disorders that share unspecific symptoms such as depression or anxiety, or by comparing subgroups of BPD patients with or without relevant comorbidity (cf. Driessen et al., 2004; Zetzsche et al., 2006). These approaches might help to elucidate the specific neural underpinnings of the observed alterations in social cognition and emotion regulation in BPD.

Finally, there are some clinical implications to be noted. High sensitivity to social cues together with a biased perception towards social rejection or threat may also be of particular relevance for psychotherapy in BPD. Given this pattern of interpersonal perception in BPD, therapists need to take special care with regard to their nonverbal signals and the patients' possible misinterpretations thereof. These situations probably mirror everyday life interactions of BPD patients and may serve as a "working point" for cognitive behavioral treatment (Linehan, 1993) or mentalization-based 
therapy (Bateman \& Fonagy, 2004; Fonagy \& Bateman, 2006). Thus, especially BPD patients who show deficits in emotion recognition might benefit from cognitive training that focuses on improving the differentiation of subtle, ambiguous social cues of the emotional states of others.

\section{REFERENCES}

Adolphs, R. (2002). Neural systems for recognizing emotion. Current Opinion in Neurobiology, 12, 169-177.

Adolphs, R. (2007). Looking at other people: Mechanisms for social perception revealed in subjects with focal amygdala damage. Novartis Foundation Symposium, 278, 146-159; discussion 160$144,216-121$.

Adolphs, R., Gosselin, F., Buchanan, T. W., Tranel, D., Schyns, P., \& Damasio, A. R. (2005). A mechanism for impaired fear recognition after amygdala damage. Nature, 433, 68-72.

Adolphs, R., \& Spezio, M. (2006). Role of the amygdala in processing visual social stimuli. Progress in Brain Research, 156, 363-378.

Adolphs, R., \& Tranel, D. (2003). Amygdala damage impairs emotion recognition from scenes only when they contain facial expressions. Neuropsychologia, 41, 1281-1289.

Adolphs, R., Tranel, D., \& Damasio, A. R. (1998). The human amygdala in social judgment. Nature, 393, 470-474.

Adolphs, R., Tranel, D., Damasio, H., \& Damasio, A. (1994). Impaired recognition of emotion in facial expressions following bilateral damage to the human amygdala. Nature, 372, 669-672.

Adolphs, R., Tranel, D., Damasio, H., \& Damasio, A. R. (1995). Fear and the human amygdala. The Journal of Neuroscience, 15, 5879-5891.

Adolphs, R., Tranel, D., Hamann, S., Young, A. W., Calder, A. J., Phelps, E. A., et al. (1999). Recognition of facial emotion in nine individuals with bilateral amygdala damage. Neuropsychologia, 37, 1111-1117.

Arntz, A., Appels, C., \& Sieswerda, S. (2000). Hypervigilance in borderline disorder: A test with the emotional Stroop paradigm. Journal of Personality Disorders, 14, 366-373.

Arntz, A., \& Veen, G. (2001). Evaluations of others by borderline patients. The Journal of Nervous and Mental Disease, 189, 513-521.

Bateman, A. W., \& Fonagy, P. (2004). Mentalization-based treatment of BPD. Journal of Personality Disorders, 18, 36-51.

Bechara, A., Damasio, H., \& Damasio, A. R. (2003). Role of the amygdala in decision-making. Annals of the New York Academy of Sciences, 985, 356-369.

Blair, R. J., Colledge, E., Murray, L., \& Mitchell, D. G. (2001). A selective impairment in the processing of sad and fearful expressions in children with psychopathic tendencies. Journal of Abnormal Child Psychology, 29, 491498.

Blair, R. J., \& Curran, H. V. (1999). Selective impairment in the recognition of anger induced by diazepam. Psychopharmacology, 147, 335-338.

Bland, A. R., Williams, C. A., Scharer, K., \& Manning, S. (2004). Emotion processing in borderline personality disorders. Issues in Mental Health Nursing, 25, 655-672.

Bolte, S., \& Poustka, F. (2003). The recognition of facial affect in autistic and schizophrenic subjects and their firstdegree relatives. Psychological Medicine, 33, 907-915.

Brambilla, P., Soloff, P. H., Sala, M., Nicoletti, M. A., Keshavan, M. S., \& Soares, J. C. (2004). Anatomical MRI study of borderline personality disorder patients. Psychiatry Research, 131, 125133.

Bush, G., Luu, P., \& Posner, M. I. (2000). Cognitive and emotional influences in anterior cingulate cortex. Trends in Cognitive Sciences, 4, 215-222.

Damasio, A. R. (1996). The somatic marker hypothesis and the possible functions of the prefrontal cortex. Philosophical Transactions of the Royal Society of London, 351, 1413-1420. 
Davis, M., \& Whalen, P. J. (2001). The amygdala: Vigilance and emotion. Molecular Psychiatry, 6, 13-34.

De La Fuente, J. M., Goldman, S., Stanus, E., Vizuete, C., Morlan, I., Bobes, J., et al. (1997). Brain glucose metabolism in borderline personality disorder. Journal of Psychiatric Research, 31, 531-541.

Devinsky, O., Morrell, M. J., \& Vogt, B. A. (1995). Contributions of anterior cingulate cortex to behaviour. Brain, 118, 279-306.

Dolcos, F., \& McCarthy, G. (2006). Brain systems mediating cognitive interference by emotional distraction. The Journal of Neuroscience, 26, 2072-2079.

Domes, G., Czieschnek, D., Weidler, F., Berger, C., Fast, K., \& Herpertz, S. C. (2008). Recognition of facial affect in borderline personality disorder. Journal of Personality Disorders, 22, 135147.

Domes, G., Winter, B., Schnell, K., Vohs, K., Fast, K., \& Herpertz, S. C. (2006). The influence of emotions on inhibitory functioning in borderline personality disorder. Psychological Medicine, 36, 1163-1172.

Donegan, N. H., Sanislow, C. A., Blumberg, H. P., Fulbright, R. K., Lacadie, C., Skudlarski, P., et al. (2003). Amygdala hyperreactivity in borderline personality disorder: Implications for emotional dysregulation. Biological Psychiatry, 54, 1284-1293.

Driessen, M., Beblo, T., Mertens, M., Piefke, M., Rullkoetter, N., Silva-Saavedra, A., et al. (2004). Posttraumatic stress disorder and fMRI activation patterns of traumatic memory in patients with borderline personality disorder. Biological Psychiatry, 55, 603-611.

Driessen, M., Herrmann, J., Stahl, K., Zwaan, M., Meier, S., Hill, A., et al. (2000). Magnetic resonance imaging volumes of the hippocampus and the amygdala in women with borderline personality disorder and early traumatization. Archives of General Psychiatry, 57, 1115-1122.

Dziobek, I., Fleck, S., Kalbe, E., Rogers, K., Hassenstab, J., Brand, M., et al. (2006). Introducing MASC: A movie for the assessment of social cognition. Journal of Autism and Developmental Disorders, 36, 623-636.
Ebner-Priemer, U. W., Kuo, J., Kleindienst, N. Welch, S. S., Reisch, T., Reinhard, I., et al. (2007). State affective instability in borderline personality disorder assessed by ambulatory monitoring. Psychological Medicine 37(7), 961-970.

Eckman, P., \& Friesen, W. V. (1976). Pictures of facial affect. Palo Alto: Consulting Psychologists.

Eippert, F., Veit, R., Weiskopf, N., Erb, M., Birbaumer, N., \& Anders, S. (2007). Regulation of emotional responses elicited by threat-related stimuli. $\mathrm{Hu}-$ man Brain Mapping, 28, 409-423.

Erthal, F. S., de Oliveira, L., Mocaiber, I., Pereira, M. G., Machado-Pinheiro, W., Volchan, E., et al. (2005). Load-dependent modulation of affective picture processing. Cognitive, Affective \& Behavioral Neuroscience, 5, 388-395.

Etkin, A., Egner, T., Peraza, D. M., Kandel, E. R., \& Hirsch, J. (2006). Resolving emotional conflict: A role for the rostral anterior cingulate cortex in modulating activity in the amygdala. Neuron, 51, 871-882.

Fitzgerald, D. A., Angstadt, M., Jelsone, L. M., Nathan, P. J., \& Phan, K. L. (2006). Beyond threat: Amygdala reactivity across multiple expressions of facial affect. Neuroimage, 30, 14411448.

Fonagy, P., \& Bateman, A. W. (2006). Mechanisms of change in mentalizationbased treatment of BPD. Journal of Clinical Psychology, 62, 411-430.

Glascher, J., Rose, M., \& Buchel, C. (2007). Independent effects of emotion and working memory load on visual activation in the lateral occipital complex. Journal of Neuroscience, 27, 43664373.

Hamann, S. B., \& Adolphs, R. (1999). Normal recognition of emotional similarity between facial expressions following bilateral amygdala damage. Neuropsychologia, 37, 1135-1141.

Haxby, J. V., Hoffman, E. A., \& Gobbini, M. I. (2002). Human neural systems for face recognition and social communication. Biological Psychiatry, 51, 59-67.

Hazlett, E. A., New, A. S., Newmark, R., Haznedar, M. M., Lo, J. N., Speiser, L. J., et al. (2005). Reduced anterior and posterior cingulate gray matter in borderline personality disorder. Biological Psychiatry, 58, 614-623. 
Herpertz, S. C., Dietrich, T. M., Wenning, B., Krings, T., Erberich, S. G., Willmes, K., et al. (2001). Evidence of abnormal amygdala functioning in borderline personality disorder: A functional MRI study. Biological Psychiatry, 50, 292298.

Johnson, P. A., Hurley, R. A., Benkelfat, C., Herpertz, S. C., \& Taber, K. H. (2003). Understanding emotion regulation in borderline personality disorder: Contributions of neuroimaging. The Journal of Neuropsychiatry and Clinical Neurosciences, 15, 397-402.

Juengling, F. D., Schmahl, C., Hesslinger, B., Ebert, D., Bremner, J. D., Gostomzyk, J., et al. (2003). Positron emission tomography in female patients with borderline personality disorder. Journal of Psychiatric Research, 37, 109115.

Kohler, C. G., Anselmo-Gallagher, G., Bilker, W., Karlawish, J., Gur, R. E., \& Clark, C. M. (2005). Emotion-discrimination deficits in mild Alzheimer disease. American Journal of Geriatric Psychiatry, 13, 926-933.

Kohler, C. G., Turner, T. H., Bilker, W. B., Brensinger, C. M., Siegel, S. J., Kanes, S. J., et al. (2003). Facial emotion recognition in schizophrenia: Intensity effects and error pattern. American Journal of Psychiatry, 160, 1768-1774.

Korfine, L., \& Hooley, J. M. (2000). Directed forgetting of emotional stimuli in borderline personality disorder. Journal of Abnormal Psychology, 109, 214-221.

Leppanen, J. M. (2006). Emotional information processing in mood disorders: A review of behavioral and neuroimaging findings. Current Opinions in Psychiatry, 19, 34-39.

Levine, D., Marziali, E., \& Hood, J. (1997). Emotion processing in borderline personality disorders. Journal of Nervous and Mental Disease, 185, 240-246.

Lieb, K., Zanarini, M. C., Schmahl, C., Linehan, M. M., \& Bohus, M. (2004). Borderline personality disorder. Lancet, 364, 453-461.

Linehan, M. M. (1993). Cognitive-behavioral treatment for borderline personality disorder. New York: Guilford.

Linehan, M. M. (1995). Understanding borderline personality disorder. New York: Guilford Press.

Lynch, T. R., Rosenthal, M. Z., Kosson, D. S.,
Cheavens, J. S., Lejuez, C. W., \& Blair, R. J. (2006). Heightened sensitivity to facial expressions of emotion in borderline personality disorder. Emotion, 6, 647-655.

Lyoo, I. K., Han, M. H., \& Cho, D. Y. (1998). A brain MRI study in subjects with borderline personality disorder. Journal of Affective Disorders, 50, 235243.

Marsh, A. A., \& Ambady, N. (2007). The influence of the fear facial expression on prosocial responding. Cognition \& Emotion, 21, 225-247.

Minzenberg, M. J., Fan, J., New, A. S., Tang, C. Y., \& Siever, L. J. (2007). Frontolimbic dysfunction in response to facial emotion in borderline personality disorder: An event-related fMRI study. Psychiatry Research, 155, 231-243.

Minzenberg, M. J., Poole, J. H., \& Vinogradov, S. (2006). Social-emotion recognition in borderline personality disorder. Comprehensive Psychiatry, 47, 468-474.

Montagne, B., Schutters, S., Westenberg, H. G., van Honk, J., Kessels, R. P., \& de Haan, E. H. (2006). Reduced sensitivity in the recognition of anger and disgust in social anxiety disorder. $\mathrm{Cog}$ nitive Neuropsychiatry, 11, 389-401.

New, A. S., Hazlett, E. A., Buchsbaum, M. S. Goodman, M., Mitelman, S. A., Newmark, R., et al. (2007). Amygdalaprefrontal disconnection in borderline personality disorder. Neuropsychopharmacology, 32, 1629-1640.

Ochsner, K. N., Bunge, S. A., Gross, J. J., \& Gabrieli, J. D. (2002). Rethinking feelings: An FMRI study of the cognitive regulation of emotion. Journal of Cog nitive Neuroscience, 14, 1215-1229.

Ochsner, K. N., Ray, R. D., Cooper, J. C., Robertson, E. R., Chopra, S., Gabrieli, J. D., et al. (2004). For better or for worse: Neural systems supporting the cognitive down- and up-regulation of negative emotion. Neuroimage, 23, 483499.

Phan, K. L., Wager, T., Taylor, S. F., \& Liberzon, I. (2002). Functional neuroanatomy of emotion: A meta-analysis of emotion activation studies in PET and fMRI. Neuroimage, 16, 331-348.

Phan, K. L., Wager, T. D., Taylor, S. F., \& Liberzon, I. (2004). Functional neuroimaging studies of human emotions. CNS Spectrum, 9, 258-266. 
Phelps, E. A. (2006). Emotion and cognition: Insights from studies of the human amygdala. Annual Review of Psychology, 57, 27-53.

Posamentier, M. T., \& Abdi, H. (2003). Processing faces and facial expressions. Neuropsychology Review, 13, 113-143.

Pretzer, J. (1990). Borderline personality disorder. In T. A. Beck \& A. Freemann (Eds.), Cognitive therapy of personality disorders (pp. 176-207). New York: Guilford Press.

Rusch, N., van Elst, L. T., Ludaescher, P., Wilke, M., Huppertz, H. J., Thiel, T., et al. (2003). A voxel-based morphometric MRI study in female patients with borderline personality disorder. $\mathrm{Neu}$ roimage, 20, 385-392.

Rusch, N., Weber, M., Il'yasov, K. A., Lieb, K., Ebert, D., Hennig, J., et al. (2007). Inferior frontal white matter microstructure and patterns of psychopathology in women with borderline personality disorder and comorbid attention-deficit hyperactivity disorder. Neuroimage, 35, 738-747.

Schmahl, C., Bohus, M., Esposito, F., Treede, R. D., Di Salle, F., Greffrath, W., et al. (2006). Neural correlates of antinociception in borderline personality disorder. Archives of General Psychiatry, 63, 659-667.

Schmahl, C. G., Elzinga, B. M., Vermetten, E., Sanislow, C., McGlashan, T. H., \& Bremner, J. D. (2003). Neural correlates of memories of abandonment in women with and without borderline personality disorder. Biological Psychiatry, 54, 142-151.

Schmahl, C. G., Vermetten, E., Elzinga, B. M., \& Bremner, J. D. (2004). A positron emission tomography study of memories of childhood abuse in borderline personality disorder. Biological Psychiatry, 55, 759-765.

Schmahl, C. G., Vermetten, E., Elzinga, B. M., \& Douglas Bremner, J. (2003). Magnetic resonance imaging of hippocampal and amygdala volume in women with childhood abuse and borderline personality disorder. Psychiatry Research, 122, 193-198.

Schnell, K., Dietrich, T., Schnitker, R., Daumann, J., \& Herpertz, S. C. (2007). Processing of autobiographical memory retrieval cues in borderline personality disorder. Journal of Affective Disorders, 97, 253-259.
Sieswerda, S., Arntz, A., Mertens, I., \& Vertommen, S. (2007). Hypervigilance in patients with borderline personality disorder: Specificity, automaticity, and predictors. Behaviour Research and Therapy, 45, 1011-1024.

Silbersweig, D., Clarkin, J. F., Goldstein, M., Kernberg, O. F., Tuescher, O., Levy, K. N., et al. (2007). Failure of frontolimbic inhibitory function in the context of negative emotion in borderline personality disorder. American Journal of Psychiatry, 164, 1832-1841.

Simonian, S. J., Beidel, D. C., Turner, S. M., Berkes, J. L., \& Long, J. H. (2001). Recognition of facial affect by children and adolescents diagnosed with social phobia. Child Psychiatry and Human Development, 32, 137-145.

Soloff, P. H., Meltzer, C. C., Greer, P. J., Constantine, D., \& Kelly, T. M. (2000). A fenfluramine-activated FDG-PET study of borderline personality disorder. Biological Psychiatry, 47, 540-547.

Sprengelmeyer, R., Young, A. W., Mahn, K., Schroeder, U., Woitalla, D., Buttner, T., et al. (2003). Facial expression recognition in people with medicated and unmedicated Parkinson's disease. Neuropsychologia, 41, 1047-1057.

Stone, V. E., Baron-Cohen, S., Calder, A., Keane, J., \& Young, A. (2003). Acquired theory of mind impairments in individuals with bilateral amygdala lesions. Neuropsychologia, 41, 209-220.

Tebartz van Elst, L., Hesslinger, B., Thiel, T., Geiger, E., Haegele, K., Lemieux, L., et al. (2003). Frontolimbic brain abnormalities in patients with borderline personality disorder: A volumetric magnetic resonance imaging study. Biological Psychiatry, 54, 163-171.

Tebartz van Elst, L., Ludaescher, P., Thiel, T., Buchert, M., Hesslinger, B., Bohus, M., et al. (2007). Evidence of disturbed amygdalar energy metabolism in patients with borderline personality disorder. Neuroscience Letters, 417, 36-41.

Tebartz van Elst, L., Thiel, T., Hesslinger, B., Lieb, K., Bohus, M., Hennig, J., et al. (2001). Subtle prefrontal neuropathology in a pilot magnetic resonance spectroscopy study in patients with borderline personality disorder. The Journal of Neuropsychiatry and Clinical Neurosciences, 13, 511-514.

Vuilleumier, P., \& Pourtois, G. (2007). Distributed and interactive brain mecha- 
nisms during emotion face perception: Evidence from functional neuroimaging. Neuropsychologia, 45, 174-194.

Wagner, A. W., \& Linehan, M. M. (1999). Facial expression recognition ability among women with borderline personality disorder: Implications for emotion regulation? Journal of Personality Disorders, 13, 329-344.

Young, M. P., Scannell, J. W., Burns, G. A.,
\& Blakemore, C. (1994). Analysis of connectivity: Neural systems in the cerebral cortex. Reviews in the Neurosciences, 5, 227-250.

Zetzsche, T., Frodl, T., Preuss, U. W., Schmitt, G., Seifert, D., Leinsinger, G., et al. (2006). Amygdala volume and depressive symptoms in patients with borderline personality disorder. Biological Psychiatry, 60, 302-310. 